\title{
CS Resarch Square \\ Caving Impacts on Cave Microbial Diversity: Case Study of Morca Cave, Turkey
}

Nahdhoit AHAMADA RACHID

İstanbul Üniversitesi: Istanbul Universitesi

Nihal Doğruöz Güngör ( $\boldsymbol{\nabla}$ ndogruoz@istanbul.edu.tr)

Istanbul University: Istanbul Universitesi https://orcid.org/0000-0002-8098-039X

\section{Research Article}

Keywords: Human impact, In-situ cave microbial diversity, Cave ecosystem preservation, Morca Cave

Posted Date: January 7th, 2022

DOI: https://doi.org/10.21203/rs.3.rs-1067784/v1

License: (c) (i) This work is licensed under a Creative Commons Attribution 4.0 International License. Read Full License 


\section{Abstract}

Some microorganisms identified in cave ecosystems have been reported to play a permanent and significant role for maintaininglife in such environments. Human entrance into caves can induce some changes on cave physic-ochemical parameters which altimately affects the living organisms. In this regard, for the first time, Morca Cave was explored to evaluate the impacts that human activities may have on the microbial diversity of the cave in a limited period of time. During this expedition at a depth of $1040 \mathrm{~m}$, a camp was established for four days. Before the installation and at the end of the camp, sediments and surface samples were taken from different points of the camp area and the area around it. Sequencing of $16 \mathrm{~s}$ rRNA of each sample was performed using the next generation sequencing method. The profile of the microbial diversity before the camping reaveled that Thermoplasmata dominated the archaea group and Gamma- and Alpha-proteobacteria were the most dominant bacterial group. After the camp, a decrease in the microbial diversity especially the previously mentioned classes strains is observed at the most of the sampled areas. The results also showed that Bacilli strains significantly increased after the camp and increase of Bacteroidia strains is observed at the most active sampled areas. This present study therefore highlights how microbial diversity inside a closed cave can respond to the human activities within a short period. Furthermore, it may constitute a solid basis to support efforts targeted at improving technics for cave management and expedition for the conservation of cave nature.

\section{Introduction}

Caves are dark oligotrophic environments characterized by high humidity and a generally low but stable temperature (Tomczyk-z_ Ak and Zielenkiewicz 2016). Cave ecosystems harbour a large number of microorganisms with different features. The way microorganisms adapt tothese extreme conditions such as cave environmental conditions is more interesting due to their specific characters. Chemoautotrophic microorganisms are expected to contribute to the carbon and nitrogen cycles in their ecosystems (White and Culver 2009). In addition, caves contain important natural bioactive compounds, provided by their indigenous microorganisms, with high potential uses in different industrial and biotechnological fields (Ghosha et al. 2017; Çandıroğlu and Doğruöz Güngör 2020; Banerjee et al. 2019). Therefore, to conservez these bioactive compounds and the life inside caves, the cave microbial diversity should be protected.

However, due to anthropogenic activities such as tourism, sports and research, this fragile ecosystem is disrupted and threatened. The stability of this cave ecosystem can therefore be affected. This biodiversity maybe affected in different ways by the human activities inside or outside caves. During cave expeditions, input of organic matters inside the cave; including leaving some remains of food, accidental falling-down of hair or depositing fecal materials in the cave environment, can induce the change of the ecological structure of these ecosystems (Barton 2006; White and Culver 2009). The increase of the organic materials might also induce stress of native microorganisms or even extinction of some of them.

Other studies also reported that decrease of microbial diversity in caves can be caused by anthropogenic activities inside or around the cave ( Alonso et al. 2019). Anincrease in the levels of $\mathrm{CO}_{2}$ inside the cave 
ecosystem during expedition is reported in cave opened for tourism. Furthermore, mechanical forces applied by cavers inside the caves such as walking are reported to reduce the cave sediment oxygens (Kurniawan et al. 2017; Lavoie et al. 2006). Human flora can also be deposited inside caves by touching cave structures or other activities like leaving fecal matter. In this context, the cave microbial diversity should be investigated during the first entry to the cave in order to avoid any human related effect on this biodiversity.

Certainly investigation of the cave ecosystems for the identification of their microbial diversity is important due to their succeptible uses in medicine and biotechnological fields. However, human activities during such studies or other cave exploration activities are thought to impact on the microbial diversity. For this purpose, our study was aimed to (i) profile the microbial diversity of Morca Cave at the depth of $1040 \mathrm{~m}$ by using the Next Generation Sequencing method and (ii) evaluate the impacts caused by human activities (camping that was carried out during the first expedition of $1040 \mathrm{~m}$ of Morca Cave within a given short period of time, four days. This study will not only permit establishment of the microbial diversity of the Morca Cave for the first time and the human activities impacts on it, but it will also constitute a solid basis for future microbiological researches in this Cave.

\section{Materials And Methods}

\section{SAMPLING SITE AND SAMPLES COLLECTION}

The Morca Sinkhole is located at the Middle Taurus mountains in Turkey. Sediment and surface samples were taken from around the camping site installed at 1040 metres depth during the Morca 2019 expedition (Fig. 1; Table 1). All the samples were taken under aseptic conditions: the surface samples were collected with sterile swabs preserved in sterile saline water,the sediments were collected in sterile cups using sterile spoons, and sterile gloves were worn while sampling. Samples taken before the camp were stored in ice until the end of the camp (4 days) and together with the samples collected after the camp from the same points, were transported to the laboratory where they were stored at $-20^{\circ} \mathrm{C}$ until they were analysed. 
Table 1

Details of collected samples

\begin{tabular}{|lll|}
\hline Sample Type & Sampling period & Sampling area \\
\hline wall & Before camp & Campsite (A) \\
\hline wall & After camp & Campsite (A) \\
\hline Sediment & After camp & Campsite (B) \\
\hline Sediment & Before camp & Near toilet area 1 (E) \\
\hline Sediment & After camp & Near toilet area 1 (E) \\
\hline Sediment & Before camp & Near toilet area 2 (F) \\
\hline Sediment & After camp & Near toilet area 2 (F) \\
\hline wall & Before camp & Near campsite (C) \\
\hline wall & After camp & Near campsite (C) \\
\hline Sediment & Before camp & Near campsite (D) \\
\hline Sediment & After camp & Near campsite (D) \\
\hline
\end{tabular}

\section{DNA ISOLATION}

The genomic DNA from each sample was isolated using the 'FastDNA Spin Kit for Soil' kit according to the manufacturer procedure. The isolated DNA concentrations $(\mathrm{ng} / \mu \mathrm{l})$ were measured using a nanodrop device and run to an agarose gel under electrophoresis for the control.

ANALYSIS OF 16S rRNA AMPLICON

The V4-V5 variable region of the 16S rRNA genes from the purified DNA samples were amplified by using bacterial and archaeal universal primers 515F (5'-GTGYCAGCMGCCGCGGTAA-3') and 926R (5'-

CCGYCAATTYMTTTRAGTTT-3') following the methods from literature (Walters et al. 2015). By using this library preparation kit, the PCR was run under these conditions: primary denaturation step at $94^{\circ} \mathrm{C}$ for 3 min following by 28 cycles of $\left(94^{\circ} \mathrm{C}\right.$ for 3 seconds, $53^{\circ} \mathrm{C}$ for $40 \mathrm{sec}, 72^{\circ} \mathrm{C}$ for $60 \mathrm{sec}$ ), and the last step of elongation for $5 \mathrm{~min}$ at $72^{\circ} \mathrm{C}$. PCR products were run in $2 \%$ of agarose gel for amplification control. Each sample product's concentration was measured and compared to equimolar volume. The united amplicons were purified by using the AMPure XP (Beckman Coulter, USA) magnetic beads present inside the kit. According to the protocol of DNA library preparation kit, the united and purified samples have been made ready for sequencing. Service procurement was carried out with an average of 50000 readings (2x300 bp) for each sample on the MiSeq device for Next Generation Sequencing - NGS service.

\section{BIOINFORMATIC ANALYSES}


Quality control of the entire sequences obtained after sequencing were carried out in the FASTQC program. 16S rRNA amplicon data were analyzed using the QIIME2 software package. First, the primer sequences used in the PCR step were removed from the sequences by cutting with the cutadapt (cutadapt trim-paired) insert. Then, the forward and revers arrays were combined with the vsearch plugin (vsearch join-pairs). Combined fragment sequences obtained were applied "denoising" using the Deblur program (deblur denoise-16S). Chimeric fragments were also filtered at this stage, resulting in ASV (Amplicon sequence variants) sequences. At the same time, the reading amounts of each series among all samples were also revealed, and the taxonomic classification of each series was performed with the classifysklearn plug-in (feature-classifier classify-sklearn), using the SILVA_132 database. Percentage reading rates in each taxonomic unit were calculated, and the bacterial and archaeal microbiota content of each sample was revealed. Alpha rarefaction analysis was also performed in the QIIME2 software package (diversity alpha-rarefaction): Chao1, Observed_OTUs, Shannon and Simpson metrics were calculated with the diversity alpha command.

\section{T-TEST STATISTICAL ANALYSIS}

Differences between samples taken before the camp and those taken after the camp were statistically determined through T-test statistical analysis with the critical value $a=0.05$. This test was applied on four taxonomic levels : phylum, class, and genus.

\section{Results}

\section{OBSERVED DIFFERENCES IN THE MICROBIAL DIVERSITY BETWEEN SAMPLES COLLECTED BEFORE AND AFTER THE CAMP}

A total of 1561 OTUs was identified from the total of the samples taken before camping against 1920 OTUs identified after (Table 2). Both archaea and bacteria were determined in this study area. Both before and after camping, archaea were observed with a relative abundance lower than that of bacteria. Before camping,the archaea in $\mathrm{B}, \mathrm{E}, \mathrm{F}$, and $\mathrm{D}$ areas, were $0.35 \%, 3.77 \%, 0.28 \%$, and $0.02 \%$ respectively. However, the points $A$ and $C$ registered an abundance rate less than $0.01 \%$ of archaea. Aftercamping, a decrease in the abundance of archaea was observed in areas $B$ and $C$ while it was increased in areas $D$ and $F$. 
Table 2

Alpha diversity of each sampling area.

\begin{tabular}{|llllll|}
\hline $\begin{array}{l}\text { sampling } \\
\text { area }\end{array}$ & $\begin{array}{l}\text { sampling } \\
\text { period }\end{array}$ & chao1 & observed_otus & shannon & simpson \\
\hline A & NAR1 & 143,84 & 143 & 4,333666832 & 0,896421666 \\
\hline A & NAR2 & 141,0731707 & 141 & 3,212326362 & 0,772977034 \\
\hline B & NAR3 & 181,7142857 & 181 & 5,552910745 & 0,945450354 \\
\hline B & NAR4 & 342,185567 & 338 & 5,57312221 & 0,929612327 \\
\hline E & NAR5 & 253,4705882 & 248 & 5,290159065 & 0,914834489 \\
\hline E & NAR6 & 539,1818182 & 534 & 6,588622341 & 0,963566081 \\
\hline F & NAR9 & 438 & 433 & 6,620141902 & 0,9687542 \\
\hline F & NAR10 & 260,9710145 & 259 & 5,857635488 & 0,953874902 \\
\hline C & NAR11 & 99,32258065 & 99 & 2,721648905 & 0,700177309 \\
\hline C & NAR12 & 69,75 & 68 & 3,347061491 & 0,812636098 \\
\hline D & NAR13 & 461,0930233 & 457 & 6,3075618 & 0,95749345 \\
\hline D & NAR14 & 585,9482759 & 580 & 6,773397309 & 0,966900149 \\
\hline NAR1, NAR3, NAR5, NAR9, NAR11, and NAR13 represent data of the pre-camping period; NAR2, NAR4, & \\
\hline NAR6, NAR10, NAR12, and NAR14 represent data of the post-camping period. & \\
\hline
\end{tabular}

Besides the archaea, bacteria identified in the samples taken before camping composed of 25 phyla dominated by Proteobacteria, Actinobacteria, Bacteroidetes, Firmicutes, Planctomycetes,

Gemmatimonadetes, and Acidobacteria. It must be noted here that the indigenous microbial community of this part of Morca Cave under study was represented by the results observed on samples taken before the camping. The community composition of each specific sampling area is detailed and community differences between the two periods were evaluated on the class and genus levels.

- Camp site (surface samples) (A)

The Chao1 of the Alpha diversity which indicates the species richness was noted to be sightly high before the camping period (143.8 against 141). Shannon index, which calculates the species diversity by considering both the richness and the equitability of the species, showed a high diversity of species before the camping period (4.3 against 3.2). It is the same for the Simpson index which shown that this site had a high microbial diversity before camping ( 0.89 against 0.77 ) (Table 2$)$. The taxonomic analysis of this site revealed that there was no archaea in the two sampling periods. Even if mostbacteria in this area were unidentified at the genus level, significant differences were noted between the two periods. 
Gamma-proteobacteria, Alpha-proteobacteria and Bacilli 46.29\%, 29.18\% and $10.59 \%$ respectively were the most dominant classes observed before the camp. Important differences were observed for Alphaproteobacteria and Bacilli classes. While the Alpha-proteobacteria decresed by $21.7 \%$, the Bacilli class significantly $(p=0,003)$ increased parallel to its phylum (Firmicutes) by 33.83\% (Fig. 2). At genus level, Acinetobacter (23.25\%), Brevundimonas (19.41\%), Massilia (9.84\%), Aerococcus (7.65\%), Pseudomonas (5.34\%) and wb1-P19 (4.48\%) were the most abundant ones before the camping activities. Acinetobacteria increased by $7.37 \%$ while Brevundimonas and Pseudomonas decreased after the camping period by $17.97 \%$ and $5.34 \%$ respectivetly. In addition, Exiguobacterium belonging the class Bacilli, which was almost absent before the camping shown a significantly increase rate (33.3\%).

- Camp site: sediment samples (B)

Chao1 index values for the two periods were 181.7 and 342.1 before and after camping respectively. These values shown an augmentation of species biomass after camping in this sampling area. The species diversity evaluated using Shannon and Simpson indices did not show important variation between these two periods: the Shannon index and the Simpson index before and after camping were 5.55 and 5.57, were 0.94 and 0.92 respectively (Table 2$)$. In this area, both the Thermoplasmata $(0.25 \%)$ and Nitrososphaeria $(0.1 \%)$ classes of the archaea represented $0.35 \%$ of the microbial biomass. On the other hand, after the camp this microbial group was absent (Fig. 3).

In addition, the bacterial group before camping was dominated by Gamma-proteobacteria with a relative abundance rate of $47.01 \%$, followed by Actinobacteria (16.64\%), and Alpha-proteobacteria $(13.12 \%)$. However, after the camping period, it was observed that while Gamma-proteobacteria had increased (11.98\%), Actinobacteria shown a decrease of (11.25\%) (Fig. 3). Genera Pseudomonas (17.04\%) and Acinetobacter(14.18\%), Wb1-P19 (6.03\%), Variovorax (2.06\%), Sphingorhabdus (8.70\%), Nocardioides (2.36\%), Gaiella (1.61\%), Paeniglutamicibacter (1.31\%) and Pir4_lineage (1.01\%) were the most abundant species before camping. At the end of camping, Pseudomonas, Acinetobacter, and Sphingorhabdus decreased by $15.3 \%, 5.08 \%$, and $6.59 \%$ while wb1-P19 and Limnobacter increased at the end of the camping period $11.59 \%$ and $15.68 \%$ respectively.

- Near the toiletarea 1 (E)

According to Chao1, Shannon and Simpson indices microbial biomass and diversity increased in this area after the camping (Table 2). This area shown the highest archaea biomass (3.7\%) among all the sampling sites (Fig. 4). The following classes were identified Thermoplasmata (2.96\%), Woesearchaeia $(0.06 \%)$ and Nitrososphaeria $(0.75 \%)$ classes with Candidatus Nitrososphaera being the sole genus. The highest rate of archaea remained uncultured archaeon. After the camping period, the abundance of each class decreased (Fig. 4).

The classes Actinobacteria (39.03\%) and Gamma-proteobacteria (25.09\%) dominated this site before the camping. Other classes like NC10 (7.47\%), Alpha-proteobacteria (3.02\%) and Planctomycetacia (1.71\%) were also identified. However, after the camping it observed that Actinobacteria as well as Gammaproteobacteria classes decreased by $34.03 \%$ and 10.34 respectively. On the other hand, a significant 
increment in Bacilli and Clostridia classes $44.21 \%$ and $8.49 \%$ respectively were noted after the camping (Fig. 4). It is also important to mention that there was a decrease in Nitrospira strains $(0.28 \%)$ in this area. Genera Nocardioides, Variovorax, Alkanindiges, Acinetobacter, and Massilia of unidentified genus belonging the family Micrococcaceae of phylum Actinobacteria were identified before the camping with the respective rates of $19.58 \%, 8.22 \%, 2.93 \%, 2.49 \%$ and $2.09 \% .19 .08 \%$. At this level, Nocardioides and Variovorax decreased by $19.58 \%$ and $8.22 \%$ respectively after the camping period. Furthermore, Exiguobacterium, Brevibacillus, and Bacillus also increased by $14.76 \%, 12.46 \%$, and $4.72 \%$ respectively in the post-camping period with the respective increase rates.

- Near the toilets area 2 (F)

The Table 2 show a lowering of species richness, through the Chao 1 index values, in this area. Behind that, the Simpson and Shannon indices shown a drop of the microbial diversity after the camp with 0.96 and 6.58 before the camping period against 0.95 and 5.85 at the camping end, respectively. These values shown that this sampling area (before the camp) housed the most microbial diversity among all the studied points (Table 2). Archaea strains identified in this site before the camp period were composed of Thermoplasmata $(0.03 \%)$, Woesearchaeia $(0.03 \%)$ and Nitrososphaeria $(0.21 \%)$ classes. Contrary to the diversity, the biomass of archaea $(0.76 \%)$ observed before the camping was increased at the end of the camping. Thermoplasmata strains increased by $0.64 \%$ while strains of Woesearchaeia and Nitrososphaeria decreased after the camp with the respective decrease rates (0.03\%) and (0.12\%) (Fig. 5). In addition, the bacterial group composed of 20 phyla with a highly diversified class level dominated by Gamma-proteobacteria (52.72\%) at the pre-camping period. The Bacilli (9.61\%), Alpha-proteobacteria (7.37\%), NC10 (6.02\%), Actinobacteria (2.66\%), and Planctomycetacia (2.36\%) have also identified at abundance rates $>1 \%$. Important variations were noted between the two sampling periods on Gammaproteobacteria and Bacilli classes which shown respectively a decrease rate of $12.61 \%$ and an increase rate of $11.49 \%$ (Fig. 5). In this second point near the toilet area, the camping end was also marked by a decrease of members of Nitrospira strains (0.18\%). In addition, genera Pseudomonas (9.99\%), wb1-P19 (9.17\%), Massilia (4.48\%), Bacillus (4.45\%), Candidatus Methylomirabilis (3.43\%), Acinetobacter (2.95\%) and Brevibacillus (2.76\%) were identified before the installation of the camp. The significant change at this level was observed on the genus Acinetobacter which shown an increase rate of $13.5 \%$ after the camp.

- Near the camp site: Surface samples (C)

Results of alpha diversity analyses shown that this site has the lowest microbial count and diversity (Table 2). The Chao1 index before the camp was 99.3 while after the camp was 69.75 . Contrary to that, the diversity of this area increased at the end of the camp. The Shannon and Simpson indexes were respectively 2.72 and 0.70 before the camp period against 3.34 and 0.81 at the end of the camp (Table 2). Before as well as after the camp, archaea strains were absent $(0.0 \%)$ in this site. The bacterial community was dominated by strains of Gamma-proteobacteria $(69.51 \%)$ and Alpha-proteobacteria (37.92\%). However, their abundances decreased by respectively $31.92 \%$ and $18.47 \%$ at the end of the 
camping. Strains of Bacilli class became dominants in this area by showing an increase rate of $49.01 \%$ (Fig. 6). Furthermore, our results revealed that Acinetobacter (56.37\%), Brevundimonas $(23.36 \%$ ) and Massilia (7.71\%) dominated the area before the camping period. At the end of the camping period, genera Acinetobacter and Brevundimonas were observed with respective decrease rates of $28.11 \%$ and $22.65 \%$ contrary to the genera Exiguobacterium and Sphingomonas which shown significant increase rates of respectively $36.54 \%$ and $5.24 \%$.

- Near the camp site: Sediment samples (D)

Compared to all the other studied points, this site shown the highest species richness at the two sampling periods. The Chao1 index, of the Alpha diversity, was 461.09 before camping and $585.9 \%$ at the end of the camping period (Table 2). Both Shannon and Simpson indices shown an augmentation of the diversity after the camping period (Table 2 ). Before the camp, the abundance of archaeal community in this site was weak and almost composed by strains of Nitrososphaeria class $(0.02 \%)$. The increase of diversity and biomass of this community after the camp period is marked by the increase of Nitrososphaeria strains $(0.34 \%)$ and the appearance of Thermoplasmata $(0.10 \%)$. On the other hand, the bacterial class level at the pre-camping period, is largely dominated by Gamma-proteobacteria (54.61\%) followed by Alpha-proteobacteria (9.88\%). However, at the post-camping period, the class Gammaproteobacteria decreases by $37.58 \%$ while Bacilli and Actinobacteria classes increased significantly with (28.86\%) and (8.3\%) as respective rates (Fig. 7). The genera wb1-P19 (14.26\%), Massilia (8.70\%) and Acinetobacter (5.76\%) are the most dominant at the pre-camping period. Pseudomonas, Sphingomonas, Brevundimonas, Bacillus, Terrimonas are also identified at the genus level with relative percentage rates between $5 \%$ and $1 \%$. At the post-camping period, Massilia and Acinetobacter were nearly absent $(0.0 \%)$ and $(0.03 \%)$ while Bacillus and Micromonospora shown increase rates of $8.18 \%$ and $6.13 \%$ respectively.

\section{Discussion}

To our knowledge, this study is the first microbiological study run in the Morca Cave. It was run in a new explored part of the cave where it was the first time that cavers entered. In this fact, the samples taken before the camp may constitute the profile of microbial community of this part of the cave.

In this study, the abundance rate of archaea observed in samples taken before the camp was extremely lower than that of bacteria observed in the same samples. Even if every cave ecosystem presents its own and proper microbial community, our observation of archaea in this Morca cave part is consistent to most of studies conducted in other cave ecosystems (Kimble et al. 2018; Jurado et al. 2020). The genus Candidatus Nitrososphaera belonging phylum Thaumarchaeota is the unique identified archaea's genus in our study. It is well known as ammonium oxidizer ( $\mathrm{K}$,mble et al. 2018; Marques et al. 2018; Baskaran et al. 2020). Hence, this archaeon is reported to be one of the major chemolithotroph in oligotrophic environment such as cave ecosystem. Zhao et al. (2017) showed the dominance of Ammonia Oxidizing Archaea in Ammonia Oxidizing communities (especially Thaumarchaeota) within Alkaline Cave 
sediments. This archaeon may have a vital function in the Morca Cave due its role in the nitrogen cycle as ammonium oxidizer.

The order Methanomassiliicoccales belonging the class Thermoplasmata (phylum Euryarchaeota), which is the most abundant class of archaea in this part of the cave, is composed of mainly uncultured methanogen archaea (Borrel et al. 2014). In the present study, these archaea are observed in the two sites near the toilet sites. Furthermore, they are composed of only uncultured archaeon starting from the family level. This order is among the seven orders belonging Euryarchaeota that are reported as most biogenic methane producers of the deep biosphere (Sar et al. 2019; Doğruöz-Güngör 2020). In general, methane producer archaea produce methane under anaerobic conditions if inorganic matters like oxygen, nitrate, and sulphate are limited (Evans et al. 2019). The presence of such microorganisms in cave ecosystems may be related to the oligotrophic and low oxygen characteristics of these ecosystems. Since methane present in the environment plays a role in the carbon cycle and contribute to the environmental nutrient as well as the weather of the environment (Evans et al. 2019), such microorganisms identified in this studied cave may played an important vital role in this cave ecosystem. In other hand, the class Woesearchaeia belonging the phylum Nanoarchaeota is also identified at the pre-camping period in area $\mathrm{E}$ and $\mathrm{F}$. Even if information about the function of these archaea strains in cave ecosystems is still limited, they were previously reported from different cave environments and other soil samples (Jurado et al. 2020; Wang et al. 2020).

Some Proteobacteria are known for their ability to decompose organic material present in cave ecosystems (Tomczyk-z_ Ak and Zielenkiewicz 2016; Barton and Jurado 2007). These microorganisms largely represented by Gamma- and Alpha-proteobacteria classes dominated all the studied areas before the camp except area E dominated by Actinobacteria. Accordingly, genera like Acinetobacter, Pseudomonas, Wb1-P19, Brevundimonas, and Massilia were the most dominants. In the formation of karstic caves and cave speleothems, the role of some bacteria through different metabolic ways is evident. When atmospheric $\mathrm{CO}_{2}$ interacts with the water molecules from the water which fall into the cave, they form carbonate ions as one of their products. These ions will further be used by some bacteria in the presence of cave calcium minerals to form the precipitated product 'calcium carbonate' which is the main composed material of karstic caves (Mengmeng et al. 2019; Gan et al. 2020; Rusznyák et al. 2012).

Acinetobacter and Pseudomonas species isolated from some karstic caves have been in-vitro determined with their ability to precipitate calcium carbonate (Türkgenci and Doğruöz-Güngör 2021). The identification of these bacteria in our study may respond to their principal role in such karstic ecosystem. On the other hand, Massilia are found to utilize large number of carbohydrates as well as other organic compounds as carbon and energy sources with a simultaneous acid production (Tomczyk-z_ Ak and Zielenkiewicz 2016; Doğruöz-Güngör 2020). Its presence in caves is reported to participate in rock dissolving (Tomczyk-z_ Ak and Zielenkiewicz 2016). Through its metabolic activities, it may also play significant role in the nutrient and carbon cycle of this ecosystem. Brevundimonas species are belonging to the family Caulobacter which is reported to be able to adapt extreme environments such as 
oligotrophic caves and supporting for the growth of other microorganisms present in the same poor nutrient ecosystem (Tomczyk-z_ Ak and Zielenkiewicz 2016; Li et al. 2004).

Actinobacteria is among the most reported cave bacterial community. In this current study, its most dominant genus is Nocardioides. Species of this genus such as N. cavernae sp. nov., and N. speluncae sp. nov are previously isolated from karst caves, characterized as oligotrophic and able to support growth from wide range of substrates (Han et al. 2017; Fang et al. 2019; Growth et al. 1999; Yoon et al. 1999). It is also reported that strains of this genus have inorganic compounds and carbon monoxide oxidation ability (Lee et al. 2021). Another interesting genus identified in this study is the methanotroph Candidatus Methylomirabilis belonging phylum Rokubacteria. This is an autotroph with carbon dioxide fixation potential. In addition, species of the genus $\mathrm{Ca}$. Methylomirabilis isolated from some caves are reported to denitrifying organic compounds to generate oxygen for the oxidation of methane present in the environment (Rasigraf et al. 2014; Bendia et al. 2020). We suggest a vital role of this bacterial strains in this ecosystem. In addition, its presence might be considered for further studies in the context of methane presence possibility in this ecosystem.

\section{MICROBIAL DIVERSITY AND DISTRIBUTION RELATED TO SAMPLE TYPES}

The diversity and distribution of microbial community is affected by the ecological factors. Different sample types (sediment, rocks, air ...) contain different chemicals and may show different physical properties. In addition, the different environmental conditions observed in every cave which are related to the geological position of the cave ecosystems caused that every cave is unique. The microbial diversity in caves is previously shown that is dependent to the sample type (sediment, rock, air, water ...) as well as the cave type (Zhu et al. 2019; Dong et al. 2020). In our study, wall samples (areas A and C) were observed with low microbial diversity than the sediment samples (Table 2). Similarly, Zu et al. (2019) observed that the higher microbial diversity and abundance was in sediment samples than in rock samples. However, Dong et al. (2020) shown completely different results in which they obtained a high microbial diversity in rocks than in soil samples. This explains that the microbial community composition and distribution of cave ecosystems is not only related to the sample type but also to the biotic and abiotic factors of the cave sampling area.

\section{HUMAN ACTIVITIES IMPACTS ON MICROBIAL BIOMASS AND DIVERSITY}

The decrease of the microbial diversity of the underground habitats such as caves are thought to be caused by anthropogenic effects (Ikner et al. 2007). In addition, low archaeal diversity is observed in more entropized caves (Alonso et al. 2019). In our study, decrease of microbial diversity is observed in the campsite (A) and the toilet area2 (F) after the camp. Besides, diminution of archaea diversity is noted near the toilet area $2(\mathrm{E})$ and the campsite $(\mathrm{B})$ after the camping period. This might be explained by the fact that these areas were suggested to be the most impacted areas during the camping period. 


\section{IMPACTS OF CAMPING ON MICROBIAL TAXONOMY}

- Analysing our results, it is observed that Protebacteria dominated the studing ecosystem before the camp while Gram (+) bacteria were the most dominants in this ecosystem after the camp. It is suggested that high number of visitors inside caves may induce the increase of the Gram (+) bacteria and the decrease of Gram (-) ones (Kukla et al. 2018). It could be speculated that the number of cavers in this camp have negatively impacts on the ecosystem bacterial community.

The dominance of Firmicutes due to anthropogenic impacts was observed in different studies. In the Kartchner Caverns, Ikner et al. (2007) found through culture based methods that high abundance of Firmicutes was in low and medium tourist impacted cave areas. Similar results are observed in the medium touristic Cave of Bats through sequencing the 16S rRNA of cave samples (Urzì et al. 2010; Tomczyk-z_ Ak and Zielenkiewicz 2016). Furthermore, the high abundance of Firmicutes in the disturbed zone of sediments from coastal area was related to the anthropogenic activities in that zone (Su et al. 2018). The statistical analyses in our study show significant increase of Firmicutes strains $(\rho=0.003$; $r<0.5)$ after the camp period. According to the previous studies this observation may be related to the human impacts in this environment.

Accordingly, all sampling sites shown important decrease of Proteobacteria (Gamma- and Alphaproteobacteria) except the campsite (B). It is important to note that this site was highly active during the emplacement of the camp as well as during the camping period as explained in the report of Usuloğlu et al. (2019). Furthermore, we should note that this point was the entrance of the tent pitching for the camp. Consequently, the increase of Proteobacteria in this area is thought to be resulted from the mixing of microorganisms from different areas of this studying part of Morca Cave. Even if a high dominance of Proteobacteria strains was reported as the result of high organic compound input, this conclusion was based on culture-dependent method (Ikner et al. 2007). In this actual study, due to the used method (culture-independent method) and the results obtained from all the remain studied sites, the increase of Gamma- and Alpha-proteobacteria in this site cannot reflect to only a high impute of organic materials. However, studying the organic composition of samples parallely may be recommended in the future studies for a definite conclusion. On the other hand, previous studies demonstrated that Proteobacteria are usually act as primary producers in the food chain of cave ecosystems (Tomczyk-z_ Ak and Zielenkiewicz 2016). Their abundance in all samples collected before the camp may indicate their important position as a basic living source in this part of the Morca Cave. Consequently, the decrease of these strains as previously demonstrated may affect the life in this ecosystem.

An important indicator of human impact is the increase of Bacteroidetes and decrease of Nitrospirae strains (Ikner et al. 2007; Alonso et al. 2019). In this actual study, the increase of Bacteroidia strains and lowering of Nitrospira strains after the camp are observed in the sites near the toilet areas (Fig. 4 and Fig. 5). These sites are suspected to be the most impacted among all the sampling points. Human related bacteria such as E. coli, Staphylococccus aureus, Propionibacterium, and the soil thermotolerant Bacillus sp. are reported as human impact indicators (Lavoie and Northup 2006; Leuko et al. 2017; Bercea et al. 
2019; Alonso et al. 2019). Surprisingly, none of these indicators are observed in all the studied samples collected after the camp. This would simply indicate that the period of the study was not enough for the establishment (adaptation) of these ex-situ microorganisms. Further studies for different sampling periods should be run for a definitive conclusion. In addition, cave microorganisms are reported to be able to remediate the cave ecosystems by compete the ex-situ organisms introduced through anthropogenic activities (Barton and Hershey 2019). However, samples should be taken after the rest period of the cave and before a new period of activities to set such conclusion in the case of our study topic.

However, high abundance of Clostridia class in the area near the Toilet 1 (E) after the camp is observed in our study. Belonging this class, the family Clostridiaceae is also observed at the same abundance in this same sampling area after the camp. This group of bacteria is considered as one of the two major groups colonizing the human faeces (Wéry et al. 2010). Accordingly, this observation is suggested to be resulted from the anthropogenic activities in this area because strains of this class are observed in the Dzou Cave sediments from tourist campsites or near the cave entrance (Mazina et al. 2020).

\section{Conclusion}

Summary, our study aimed to evaluate the human impacts on microbial diversity of a newly explored cave in a short period of time. The results provided in this actual study revealed that the microbial diversity in this studied part is composed of low archaea abundance and a dominance of Gamma- and Alpha-proteobacteria before the camping. However, at the post-camping period, a decrease of these Proteobacteria classes is observed while the increase of Bacilli and Clostridia is noted. In addition, Increase of Bacteroidia and decrease of Nitrospira have been observed near the toilet areas. These alterations may indicate that human activities have negatively impacted on the microbial diversity of this area. In our advanced studies, samples taken from these areas after one year (cave rest period) are planning for studying possible recovery of their microbial diversity rather than the establishment of human related species.

\section{Declarations}

- ETHICS APPROVAL AND CONSENT TO PARTICIPATE

Not applicable

- CONSENT FOR PUBLICATION

Not applicable

- AVAILABILITY OF DATA AND MATERIAL

The generated raw sequencing data of the 12 studied samples were deposited into the NCBI database under these accession numbers: SAMN18256317-28. 
- COMPETING INTERESTS

Nahdhoit AHAMADA RACHID and Nihal DOĞRUÖZ GÜNGÖR declare that they have no conflict of interest.

- FUNDING

This research was financially supported by the Scientific Research Projects Unit of Istanbul University (Bilimsel Araştirma Projeleri Birimi, Istanbul Üniversitesi) under the Project number: 35041.

\section{- AUTHORS CONTRIBUTIONS}

M.Sc Nahdhoit AHAMADA RACHID : Conceptualization, Methodology, Investigation, Vizualization, Writing.

Dr Nihal DOĞRUÖZ GÜNGÖR : Project administration, Conceptualization, Writing

\section{- ACKNOWLEDGEMENTS}

Authors would like to thank the Scientific Research Projects Unit of Istanbul University for their financial support of this work. Authors thank also the Anatolian Speleology Group (ASPEG) for its help during the sampling of this work.

- AUTHORS' INFORMATION

Not applicable

\section{References}

1. Alonso L, Pommier T, Kaufmann B, Dubost A, Chapulliot D, Doré J, Douady CJ, Moënne-Loccoz Y (2019) Anthropization level of Lascaux Cave microbiome shown by regional-scale comparisons of pristine and anthropized caves. Mol Ecol 28:3383-3394. doi/pdf/10.1111/mec.15144

2. Banerjee S, Jha DK, Joshi SR (2019) Cave Microbiome for Human Welfare.. In: In: Satyanarayana T, Das T, Jhori B (eds) Microbial Diversity in Ecosystem Sustainability and Biotechnological Applications. Springer, Singapore, pp 3-30. https://doi.org/10.1007/978-981-13-8487-5_1

3. Barton HA (2006) Introduction to cave microbiology: A review for the non-specialist. J Caves Karst Stud 68:43-54. doi=10.1.1.1083.4440\&rep=rep1\&type=pdf

4. Barton HA, Hershey OS (2019) The microbial diversity of caves.. In: In: Moldovan O, Halse LK (eds) Cave Ecology. Springer, Cham, pp 69-90. https://doi.org/10.1007/978-3-319-98852-8_5

5. Barton HA, Jurado V (2007) What's up down there? Microbial diversity in caves. Microbiome 2:132138. http://hdl.handle.net/10261/61951

6. Baskaran V, Patil PK, Antony ML, Avunje S, Nagaraju VT, Ghate SD, Nathamuni S, Dineshkumar N, Alavandi SV, Vijayan KK (2020) Microbial community profiling of ammonia and nitrite oxidizing bacterial enrichments from brackishwater ecosystems for mitigating nitrogen species. Sci Rep 10:111. https://doi.org/10.1038/s41598-020-62183-9 
7. Bendia AG, Callefo F, Araújo MN, Sanchez E, Teixeira VC, Vasconcelos A, Battilani G, Pellizari VH, Rodrigues F, Galante D (2020) Metagenome-assembled genomes from Monte Cristo Cave (Diamantina, Brazil) reveal prokaryotic lineages as functional models for life on Mars. bioRxiv 185041

8. Bercea S, Nastase-Bucur R, Moldovan OT, Kenesz M, Constantin S (2019) Yearly microbial cycle of human exposed surfaces in show caves. Subterr Biol 31:1-14. doi:10.3897/subtbiol.31.34490

9. Borrel G, Parisot N, Harris HM, Peyretaillade E, Gaci N, Tottey W, Brugère JF (2014) Comparative genomics highlights the unique biology of Methanomassiliicoccales, a Thermoplasmatales-related seventh order of methanogenic archaea that encodes pyrrolysine. BMC Genom 15:1-24. https://doi.org/10.1186/1471-2164-15-679

10. Çandıroğlu B, Doğruöz Güngör N (2020) The Biotechnological Potentials of Bacteria Isolated from Parsık Cave.Turkey. Johnson Matthey Technol Rev 64:466-479. https://doi.org/10.1595/205651320X15923194903811

11. Doğruöz-Güngör N (2020) The microbial community structure of the Dupnisa cave in Kırklareli, Turkey. Acta Carsologica 49:2-3. https://doi.org/10.3986/ac.v49i2-3.8575

12. Dong Y, Gao J, Wu Q, Ai Y, Huang Y, Wei W, Weng Q (2020) Co-occurrence pattern and function prediction of bacterial community in Karst cave. BMC Genom 20:1-13. https://doi.org/10.1186/s12866-020-01806-7

13. Evans PN, Boyd JA, Leu AO, Woodcroft BJ, Parks DH, Hugenholtz P, Tyson GW (2019) An evolving view of methane metabolism in the Archaea. Nat Rev Microbiol 17:219-232. https://doi.org/10.1038/s41579-018-0136-7

14. Fang BZ, Han MX, Jiao JY, Zhang XT, Xie YG, Hozzein WN, Alkhalifah DHM, Xiao M, Li WJ (2019) Nocardioides speluncae sp. nov., a novel actinobacterium isolated from a karstic subterranean environment sample. Antonie Van Leeuwenhoek 112:857-865. https://doi.org/10.1007/s10482-01801217-9

15. Gan HM, Wengert P, Barton HA, Hudson AO, Savka MA (2020) Insight into the resistome and quorum sensing system of a divergent Acinetobacter pittii isolate from an untouched site of the Lechuguilla Cave. https://doi.org/10.1099/acmi.0.000089. Access Microbiol

16. Ghosha S, Kuisieneb N, Cheepthama N (2017) Review The cave microbiome as a source for drug discovery: Reality or pipe dream. Biochem Pharmacol 134:18-34.

https://doi.org/10.1016/j.bcp.2016.11.018

17. Groth I, Vettermann R, Schuetze B, Schumann P, Saiz-Jimenez C (1999) Actinomycetes in Karstic caves of Northern Spain (Altamira and Tito Bustillo). J Microbiol Meth 36:115-122. https://doi.org/10.1016/S0167-7012(99)00016-0

18. Han MX, Fang BZ, Tian Y, Zhang WQ, Jiao JY, Liu L, Zhang ZT, Xiao M, Wei DQ, Li WJ (2017) Nocardioides cavernae sp. nov., an actinobacterium isolated from a karst cave. Int J Syst Evol Microbiol 67:633-639. https://doi.org/10.1099/ijsem.0.001676

19. https://doi.org/10.1101/2020.07.02.185041

Page $15 / 19$ 
20. Ikner LA, Toomey RS, Nolan G, Neilson JW, Pryor BM, Maier RM (2007) Culturable microbial diversity and the impact of tourism in Kartchner Caverns, Arizona. Microb Ecol 53:30-42.

https://doi.org/10.1007/s00248-006-9135-8

21. Jurado V, Gonzalez-Pimentel JL, Miller AZ, Hermosin B, D’Angeli IM, Tognini P, Saiz-Jimenez C (2020) Microbial communities in vermiculation deposits from an Alpine cave. Front Earth Sci 8:635. https://doi.org/10.3389/feart.2020.586248

22. Kimble JC, Winter AS, Spilde MN, Sinsabaugh1 RL, Northup DE (2018) A potential central role of Thaumarchaeota in N-Cycling in a semi-arid environment, Fort Stanton Cave, Snowy River passage, FEMS Microbiol. Ecol 94:fiy173. https://doi.org/10.1093/femsec/fiy173

23. Kukla J, Holec M, Trögl J, Holcová D, Hofmanová D, Kuráň P, Honzík R (2018) Tourist traffic significantly affects microbial communities of sandstone cave sediments in the protected landscape area "Labské Pískovce"(Czech Republic): implications for regulatory measures, sustain 10 https://doi.org/10.3390/su10020396

24. Kurniawan ID, Rahmadi C, Ardi TE, Nasrullah R, Willyanto MI, Rahayu S (2017) The detection of human activities' impact on show caves environment in Pacitan, Indonesia, In: Proceedings of the 17th International Congress of Speleology. Sydney, pp 175-8

25. Lavoie KH, Northup DE (2006) Bacteria as Indicators of Human IMpact in Caves. In: Proceedings of the 17th National Cave and Karst Management Symposium, pp 44-47

26. Lee JM, Jin CZ, Park SH, Kang MK, Park DJ, Kim CJ (2021) Nocardioides antri sp. nov., Isolated from Soil in a Rock Cave. Curr Microbiol 78:2130-2135. https://doi.org/10.1007/s00284-021-02370-7

27. Leuko S, Koskienen K, Sanna L, D’Angeli IM, Wael DJ, Marcia P, Rettberg CMEP (2017) The influence of human exploration on the microbial community structure and ammonia oxidizing potential of the Su Bentu limestone cave in Sardinia, Italy. PLoS ONE 12:e180700. https://doi.org/10.1371/journal.pone.0180700

28. Li Y, Kawamura Y, Fujiwara N, Naka T, Liu H, Huang X, Ezaki T (2004) Sphingomonas yabuuchiae sp. nov. and Brevundimonas nasdae sp. nov., isolated from the Russian space laboratory Mir. Int J Syst Evol Microbiol 54:819-825. https://doi.org/10.1099/ijs.0.02829-0

29. Marques E, de LS, Gross E, Dias JCT, Pirovani CP, Rezende RP (2018) Ammonia oxidation (amoA) and nitrogen fixation (nifH) genes along metasandstone and limestone caves of Brazil. Geomicrobiol J 35:869-878. https://doi.org/10.1080/01490451.2018.1482386

30. Mazina SE, Titov AY, Kozlova EV, Popkova AV (2020) Microbiota of Aquatic and Terrestrial Habitats of the Dzou Cave. IOP Conf. Ser. Earth Environ Sci 690. https://iopscience.iop.org/article/10.1088/1755-1315/690/1/012032/meta 012032

31. Mengmeng L, Chaolin F, Satoru K, Minsheng H, Vaenyam A (2019) Bio-consolidation of cracks in masonry cement mortars by Acinetobacter sp. SC4 isolated from a karst cave. Int Biodeterior Biodegradation 141:94-100. https://doi.org/10.1016/j.ibiod.2018.03.008

32. Rasigraf O, Kool DM, Jetten MSM, Damsté JSS, Ettwiga KF (2014) Autotrophic carbon dioxide fixation via the Calvin-Benson-Bassham Cycle by the denitrifying methanotroph "Candidatus 
Methylomirabilis oxyfera". Appl Environ Microbiol 80:2451-2460.

https://doi.org/10.1128/AEM.04199-13

33. Rusznyák A, Akob DM, Nietzsche S, Eusterhues K, Totsche KU, Neu TR, Küsel K (2012) Calcite biomineralization by bacterial isolates from the recently discovered pristine karstic Herrenberg cave. Appl Environ Microbiol 78:1157-1167. https://doi.org/10.1128/AEM.06568-11

34. Sar P, Dutta A, Bose H, Mandal S, Kazy SK (2019) Deep Biosphere: Microbiome of the Deep Terrestrial Subsurface.. In: In: Satyanarayana T, Das S, Jhori B (eds) Microbial Diversity in Ecosystem Sustainability and Biotechnological Applications. Springer, Singapore, pp 225-265. https://doi.org/10.1007/978-981-13-8315-1_8

35. Su Z, Dai T, Tang Y, Huang B, Mu Q, Wen D (2018) Sediment bacterial community structures and their predicted functions implied the impacts from natural processes and anthropogenic activities in coastal area. Mar Pollut Bull 131:481-495. https://doi.org/10.1016/j.marpolbul.2018.04.052

36. Tomczyk-z_Ak K, Zielenkiewicz U (2016) Microbial Diversity in Caves. Geomicrobiol J 33:20-38

37. Türkgenci MD, Doğruöz-Güngör N (2021) Profiling of Bacteria Capable of Precipitating CaCO3 on the Speleothem Surfaces in Dupnisa Cave, Kırklareli, Turkey. Geomicrobiol J 38:816-827. https://doi.org/10.1080/01490451.2021.1964110

38. Urzì C, Leo FD, Bruno L, Albertano P (2010) Microbial diversity in Paleolithic caves: a study case on the phototrophic biofilms of the Cave of Bats (Zuheros, Spain). Microb Ecol 60:116-129. https://link.springer.com/content/pdf/10.1007/s00248-010-9710-x.pdf

39. Usuloğlu E (2019) Morca 2019. pdf report from ASPEG. Anatolian Speleogical Society

40. Usuloğlu EA (2020) The Morca Cave System 2020 expedition report. pdf from ASPEG. Anatolian Speleogical Society

41. Walters W, Hyde ER, Berg-Lyons G, Ackermann G, Humphrey G, Parada A, Gilbert JA, Jansson JK, Caporaso JG, Furhman JA, Apprill A, Knight R (2015) Improved bacterial 16S rRNA gene (V4 and V45 ) and fungal internal transcribed spacer marker gene primers for microbial community surveys. mSystems 1. https://doi.org/10.1128/mSystems.00009-15 e00009-15

42. Wang H, Bier R, Zgleszewski L, Peipoch M, Omondi E, Mukherjee A, Kan J (2020) Distinct distribution of Archaea from soil to freshwater to estuary: implications of archaeal composition and function in different environments. Front Microbiol 11. 10.3389/fmicb.2020.576661

43. Wéry N, Monteil C, Pourcher AM, Godon JJ (2010) Human-specific fecal bacteria in wastewater treatment plant effluents. Water Res 44:1873-18883. https://doi.org/10.1016/j.watres.2009.11.027

44. White WB, Culver DC (2009) Cave, Definition of. In: White WB and Culver DC (eds) The Encyclopedia of Caves. Academic Press. pp 255-259. https://doi.org/10.1016/B978-0-12-814124-3.00028-5

45. Yoon HJ, Cho YG, Lee ST, Suzuki I, Nakase T, Park YH (1999) Nocardioides nitrophenolicus sp. nov., a p-nitrophenol-degrading bacterium. Int J Syst Evol Microbiol 49:675-680. https://doi.org/10.1099/00207713-49-2-675

46. Zhao R, Wang H, Yang H, Yun Y, Barton HA (2017) Ammonia-oxidizing Archaea dominate ammoniaoxidizing communities within alkaline cave sediments. Geomicrobiol J 34:511-523. 
https://doi.org/10.1080/01490451.2016.1225861

47. Zhu HZ, Zhang ZF, Zhou N, Jiang CY, Wang BJ, Cai L, Liu SJ (2019) Diversity, distribution and cooccurrence patterns of bacterial communities in a karst cave system. Front Microbiol 10. https://doi.org/10.3389/fmicb.2019.01726,1726

\section{Figures}

\section{Figure 1}

Studying area $(10,11)$

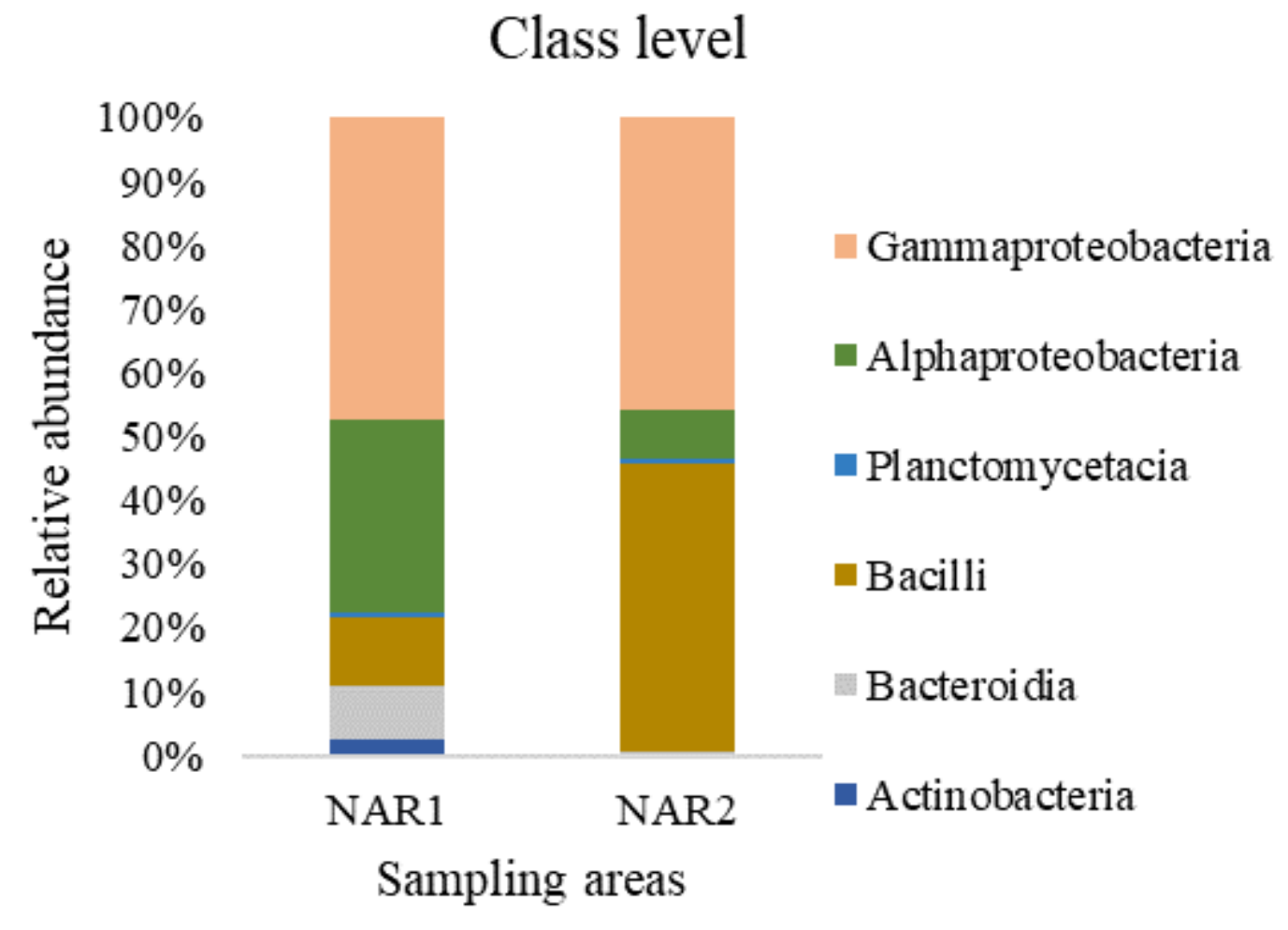

Figure 2

Observed differences at class level between samples taken before and after the camping at the area A. NAR1: before camping; NAR2: after camping

Figure 3 
Observations at class levels for samples taken before and after the camping at the area B. NAR3: before camping; NAR4: after camping

\section{Figure 4}

Significant differences observed at class level between samples taken before and after camping in the sample area E. NAR5: before camping; NAR6: after camping

\section{Figure 5}

Significance differences observed at class level between samples taken before and after the camping at the area F. NAR9: before camping; NAR10: after camping

\section{Figure 6}

Observation of significance difference at class level between samples taken before and after the camping at the area C. NAR11: before camping; NAR12: after camping

\section{Figure 7}

Significance differences observed at the class level between samples taken before and after the camping at the area D. NAR13: before camping; NAR14: after camping 